\title{
Geographic variation in the Greater horseshoe bat Rhinolophus ferrumequinum in south-eastern Europe
}

\author{
Boris KRYŠTUFEK
}

\begin{abstract}
Krystufek B. 1993. Geographic variation in the Greater horseshoe bat Rhinolophus ferrumequinum in south-eastern Europe. Acta theriol. 38: 67 - 79.

Studied was geographic variation in 12 skull measurements of 24 samples of Rhinolophus ferrumequinum (Schreber, 1774) from south-eastern Europe. Morphological principal component $1(69.5 \%$ of variance explained) was highly size related. Morphological principal component 2 (10.6\% of variance explained) correlated significantly only with interorbital constriction. Most of the interlocality variation was due to size, which increased clinally from the north-west to the south-east. Clustering of character means produced two clusters. The ranges of overlap of condylocanine length between the two size-related clusters showed no evidence of the existence of two clearly defined populations. July precipitation levels best explained the size variation observed. I propose that $R$. f. martinoi be considered a synonym of $R$. $f$. ferrumequinum.
\end{abstract}

Slovene Museum of Natural History, Presernova 20, P.O. Box 290, 61001 Ljubljana, Slovenia

Key words: Rhinolophus ferrumequinum, geographic variation, south-eastern Europe

\section{Introduction}

The number of subspecies recognized is indicative of the potential morphological variation within a species, but suggests very limited geographic variation among European bats. The Greater horseshoe bat Rhinolophus ferrumequinum (Schreber, 1774) seems to be an exception to this. During this century, European mammalogists have been dealing with up to four subspecies of Greater horseshoe bat, in addition to the nominate form. These taxa were erected mainly on slight differences in average size. Two west-European taxa, insularis and obscurus, are generally synonymized within the nominate race (e.g. Ellerman and MorrisonScott 1966, Palmeirim 1990), whereas the two races from south-eastern Europe (martinoi and creticus) appeared to merit formal recognition to the majority of authorities (Felten et al. 1977, Iliopoulou-Georgudaki and Ondrias 1986). The cranially large $R$. f. martinoi Petrov, 1941, described from the Vardar river valley in Macedonia, is reported to contact the smaller nominate race on the Balkan Peninsula (e.g. Djulić and Mirić 1967). The recently described $R$. f. creticum Iliopoulou-Georgudaki and Ondrias, 1986 is known only from the island of Crete (Iliopoulou-Georgudaki and Ondrias 1986). 
The most comprehensive elaboration of subspeciation in Greater horseshoe bai is that of Felten et al. (1977), who also supported the validity of $R$. f. martinoi. In their study Felten et al. (1977) pooled localities from within large geographic areas without overall phentotypic similarity being assessed subsequently. Such and approach is not suitable if variation is clinal, and this phenomenon was reported for forearm length in Greater horseshoe bat populations from France (Caubere et al. 1968). Although size discriminates martinoi from the nominate race, the nature of its variation in south-eastern Europe remains unclear. The aim of this article is to describe the pattern of geographic variation in skull dimensions of the Greater horseshoe bat in south-eastern Europe, to find possible climatic correlations for the morphological variation observed, and to evaluate the taxonomic position of R. f. martinoi.

\section{Material and methods}

I examined 368 Greater horseshoe bat skulls housed in the following collections: Department of Zoology, Charles University, Prague; Institute of Systematic and Ecological Biology, Czech Academy of Sciences, Brno; Naturhistorisches Museum Wien, Vienna; Natural History Museum in Belgrade; Macedonian Natural History Museum, Skopje; private collection of B. Petrov, Belgrade; and Slovene Museum of Natural History, Ljubljana. The skulls of adult animals, i.e. specimens at least in their second calendary year of life, were selected for further analyses. Sexes were combined within the samples on the basis of the finding of Felten et al. (1977) that sexual dimorphism is minimal in the Greater horseshoe bat. Finally, 295 specimens were ascribed to 24 geographic samples. In several cases I pooled localities of physiographic and climatic continuity which were expected to include the same interbreeding population. The phenotype similarity of pooled samples was first assessed by cluster analysis (UPGMA clustering on the Average taxonomic distance matrix of z-standardized data).

Listed below are the geographic samples, their designated numbers (Fig. 2) and sample sizes (in parentheses). Sample 1 - Slovakia: Drienovecka cave (12), Jasovska cave (6). Sample 2 - Slovakia: Domica cave (9). Sample 3 - Niederösterreich: Hermannshöhle (1), Diedärrischenhöhle (1), Katzelsdorf (1), Altaquelle (1), Eisensteinhöhle (1), no exact locality (1). Sample 4 - Eastern Slovenia: Paka near Velenje (1), Velika Pirešica (1), Padež (1), Liboje (1), Šentilj near Velenje (1), Mozirje (6). Sample 5 - Northwestern Slovenia: Gameljne (2), Lubnik Mt (2), Tolmin (2). Sample 6 - Borčec near Zagreb (22). Sample 7 - North Dalmatia: Manita pecina (1), Canyon of the Zrmanja river (1), Sibenik (2). Sample 8 - Novi Sad, Petrovaradin (7). Sample 9 - Belgrade, Top cider (27). Sample 10 - Eastern Serbia: Golubac (22). Sample 11 - Eastern Serbia: Zlot (14). Sample 12 - Burgas: Komunari (3), Dobromir (1). Sample 13 - Karlukovo (18). Sample 14 - Lakatnik (13). Sample 15 - Kosovo: spring of Beli Drim (12). Sample 16 - Skopje, Banjani (5). Sample 17 - Central Macedonia: Markova Kula (18), Krajnici (4), Pepeliste (3, including the type of $R$. f. martinoi). Sample 18 - Ploski (15). Sample 19 - Ohrid Lake: Cervenaka (2), Pishkash (4), Leskoec (1). Sample 20 - Vlora, Velce (21). Sample 21 - Tepelene (9). Sample 22 - Thrace: Didymontichon (8), Mandra (2). Sample 23 - Thrace, Maronia (6). Sample 24 - Island of Thassos (4).

Twelve linear measurements were taken from each of the skulls using a vernier caliper, accurate to the nearest $0.1 \mathrm{~mm}$. The abbreviations used are: $\mathrm{PL}$ - profile length, $\mathrm{CcL}$ - condylocanine length, $\mathrm{MxT}$ - maxillary tooth row length, $\mathrm{ZgB}$ - zygomatic breadth, $\mathrm{BcB}$ - braincase breadth, RoC - breadth of rostrum over canines, RoM - breadth of rostrum over molars, IoC - interorbital constriction, SdR - skull depth behind rostrum, MdL - length of mandible, MdT - mandibular tooth row length, $\mathrm{CH}$ coronoid height of mandible. 
Variations among geographic samples were analysed using one way analysis of variance. Phenetic affinities among geographic samples were assessed by Principal components analysis (PCA) on the correlation matrix of z-standardized data. A minimum spanning tree (MST) was calculated from the Average taxonomic distance (ATD) matrix among sample means, and superimposed on the plot of the projections of geographic samples onto the first two principal component axes to detect local distortions (Rohlf 1989). Clustering (UPGMA) was performed on the ATD matrix as obtained from z-standardized data.

Multivariate analyses as mentioned above were performed on sample means. Discriminant analysis encompassed the entire sample (specimens with missing values were excluded) and the two clusters recognized by the previous clustering analysis were chosen as discriminatory factors.

The object of the principal component analysis is to find combinations of original dimensions to produce principal components which are not correlated. The lack of correlation means that each principal component measures different "dimensions" of the original data set (Manly 1986). Consequently, the first two morphological principal components, which were responsible for the majority of variation in the original data set, were subjected to spatial autocorrelation analysis. Moran's autocorrelation coefficients were plotted as a function of distance between pairs of localities to summarize the patterns of geographic variation by means of correlograms (Gabriel and Sokal 1969, Sokal 1978).

Eight climatic variables were recorded for each sample, namely: TJan - mean January temperature; TJul - mean July temperature; TAnn - mean annual temperature; PJan - mean January precipitation; PJul - mean July precipitation; PAnn - mean annual precipitation; SDT - standard deviation of mean of average monthly temperatures (temperature seasonality); SDP - standard deviation of mean of average monthly precipitation (precipitations seasonality). The following sources of climatic data were used: Steinhauser (1970), Landsberg (1977), Climatic Atlas of the Socialist Federative Republic of Yugoslavia (undated). Principal components analysis on the correlation matrix of $\log _{10}$-transformed characters was used to reduce the number of independent climatic variables. The relationships between cranial data and climatic variables were assessed by stepwise multiple regression analyses.

\section{Results}

Phenetics

Four skull characters (PL, CcL, RoC, CH) out of twelve showed significant interlocality heterogeneity $(p<0.05)$. Two of them $(\mathrm{PL}, \mathrm{CcL})$ represented size, and the other two were also positively correlated with the condylocanine length of skull $(p<0.001)$ - a dimension best describing general size. Thus, we may conclude that only size is subject to interlocality geographic variation. A similar pattern of geographic variation was revealed by ordination. Morphological principal component 1 (MPC1) accounted for $69.5 \%$ of the total phenetic variance. It was positively correlated $(p<0.001)$ with all skull dimensions except interorbital constriction ( $r=-0.03$, not significant). Hence, the magnitude in size of the specimens of any sample was directly related to the magnitude of its corresponding MPC1 score. Morphological principal component 1 was thus considered a "size" factor, although some shape variation was necessarily involved. Morphological principal component 2 (MPC2; $10.6 \%$ of variance explained) was significantly correlated only with $\mathrm{IoC}(r=-0.96, p<0.001)$, and so was taken as a measure of the least interorbital constriction. As MPC1 explained most of the total variance 


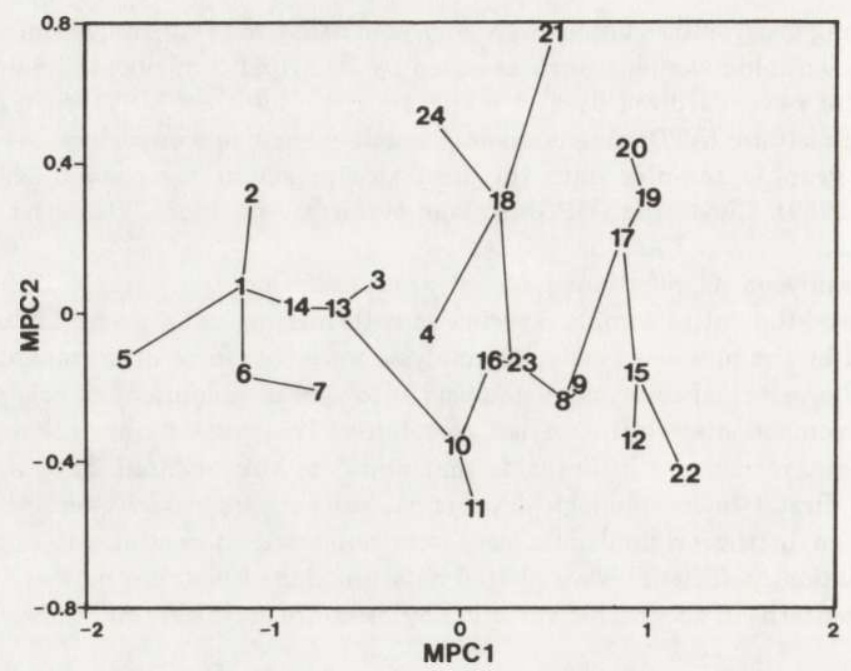

Fig. 1. Projection of 24 Rhinolophus ferrumequinum sample centroids onto the first two morphological principal components (MPC1 and MPC2). The shortest minimally connected network (MST) is represented by solid lines. Numbers refer to the samples given in Fig. 2.
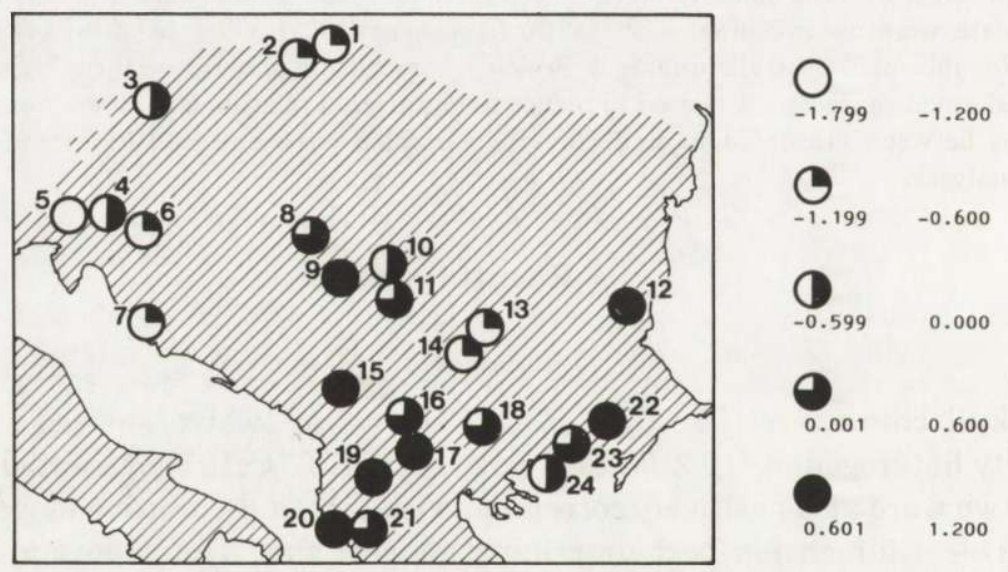

Fig. 2. Geographic variation in morphological principal component 1 (MPC1) of 24 Rhinolophus ferrumequinum localities. Pie diagrams arbitrarily divide the total range of MPC1 scores into five equal portions, but do not represent statistically homogeneous subsets. Open circles represent the smallest bats and filled circles represent the largest. For sample sizes and locality identities see text. The approximate range of the species (shaded) is according to Feriancova-Masarova and Hanák (1965), Görner and Hackethal (1987), and Bauer et al. (1979).

in the skull characters, Greater horseshoe bat samples varied primarily in size, but very little in shape. The samples were projected onto the first two morphological principal components (Fig. 1) which accounted for $80.1 \%$ of the total phenetic variance in the data. To highlight any distortion present in Fig. 1, the 
Fig. 3. UPGMA dendrogram summarizing ATD relationships among 24 Rhinolophus ferrumequinum samples from south-eastern Europe. Two clusters, designated A and B, are discussed in the text. For sample designation see Fig. 2. ATD - Average Taxonomic Distance based on 12 cranial variables. Cophenetic correlation was 0.71 .


Fig. 4. Range of variation of condylocanine length (CcL) among 24 Rhinolophus ferrumequinum samples from south-eastern Europe. Samples are listed in the same order (from left to right) as in the dendrogram (Fig. 3). Sample means within the same cluster (A and B resp.) are connected by lines. For sample designation see Fig. 2. $\bar{x}-$ total average of CcL.

minimum spanning tree (MST) was superimposed on the projection of the first two morphological principal components. Distortion mainly occurs where nearby samples on the diagram do not lie on a branch of the MST, e.g. in the case of sample 4. In general however, little distortion was suggested by the MST. We may assume that the scatter of the 24 samples on the projection of the first two morphological principal components reflects the actual phenetic relations amongst them. 
The geographic variation in MPC1 scores of the 24 samples is shown in Fig. 2. There is good agreement between the geographic origin of the sample and cranial size. Cranially small samples were limited to the north and north-west of the study area. The bats from sample 5 were the smallest of all. Additionally, there were two phenetically small populations from the mountains of eastern Bulgaria (samples 13 and 14).

Clustering revealed the existence of two clusters, designated A and B respectively (Fig. 3). Samples clustered into group A originated from northern and north-western areas and western Bulgaria, where phenetically small bats were expected from a previous ordination analysis. Cluster B was composed of samples of bats with large skulls.

The previous results were based on average skull dimension values. The total range of condylocanine length (the character having the highest correlation coefficient with PC1 as "size" factor; $r=0.93, p<0.001$ ) revealed a considerable overlap between clusters A and B (see Fig. 4). Samples 3 and 4 in cluster A were alredy within the range of phenetically large bats from cluster $B$.

\section{Taxonomic status}

The two subspecies of the Greater horseshoe bat in south- eastern Europe have been distinguished on the basis of size (Petrov 1941, Djulić and Felten 1964, Felten et al. 1977). Consequently, samples belonging to one of the two clusters (Fig. 3) were regarded as representative of the nominate race (cluster $\mathrm{A}$ ) and R. f. martinoi (cluster B) respectively. These two clusters were taken as a classificatory factors for discriminant analysis. $82.1 \%$ of the specimens of cluster A and $80.8 \%$ of the specimens from cluster B were classified into the predicted groups. The best discrimination was achieved by $\mathrm{ZgB}, \mathrm{RoC}, \mathrm{SdR}, \mathrm{MdL}, \mathrm{MdT}$, and $\mathrm{CH}$. All these variables also showed a significant positive correlation with condylocanine length $(p<0.001)$. However, the overlap between the two predicted groups was large (Fig. 5) and the frequency histogram showed no bimodality when the specimens

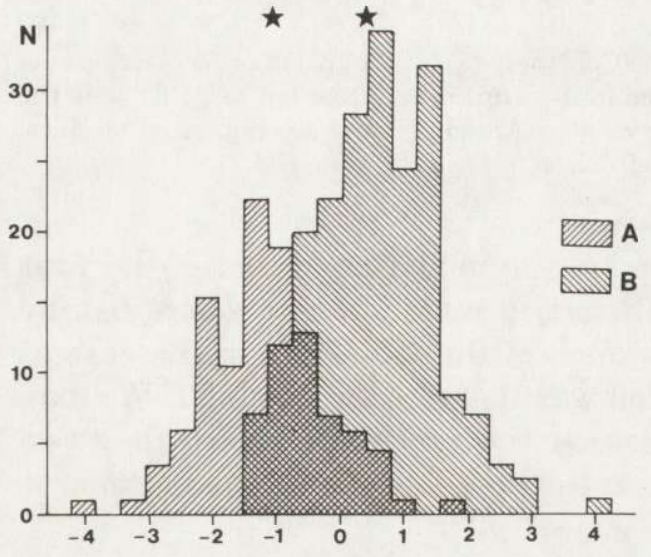

Fig. 5. Frequency distribution of discriminant scores of Greater horseshoe bats according to two clusters as obtained by previous clustering (see Fig. 3); stars designate cluster centroids. 
of all 24 samples were pooled. These results indicate that the differences between the two groups of populations are very slight.

\section{Geographic pattern of phenetic variation}

As shown before (Fig. 2) size varies along the north-west to south-east transect, with the smallest bats in the north-west. Morphological principal component 1 also showed a significant negative correlation with latitude $(r=-0.68, p<0.01)$, thus suggesting clinal variation in size. No significant correlation was found between latitude and morphological principal component $2(r=-0.30, p=0.152)$.

Consequently, it was not surprising that distance-correlated correlograms of the two morphological principal components revealed two different patterns of geographic variation (Fig. 6). The scores of MPC1 showed significant positive autocorrelation at 100 and $200 \mathrm{~km}$, and significant negative autocorrelations from 800 to $1000 \mathrm{~km}$. The regular monotonic decline that is characteristic of a cline (Sokal 1978) was obstructed at $600 \mathrm{~km}$ (significant positive autocorrelation). This was explained by the fact that Moran's autocorrelation coefficient could have been affected by the distribution of sample points, which were not regularly spaced in this study. Point pairs at $600 \mathrm{~km}$ were mainly between samples belonging to one of the two clusters (defined in Fig. 3), resulting in a positive autocorrelation. The geographic distribution of phenetically large versus small samples also suggested that the interdigitating boundary was due to the presence of samples 13 and 14 (low values of MPC1) within the area of phenetically large bats. In spite of this distortion it seems that the general pattern of size variation of the Greater



Fig. 6. Correlograms for two morphological principal components (MPC1 and MPC2) intended to simulate patterns of geographic variation in 24 samples of Rhinolophus ferrumequinum. Abscissa: distance in kilometres. Ordinate: Moran's autocorrelation coefficient I. Significant autocorrelation coefficients $(p<0.05)$ are indicated by circles. 
horseshoe bat is clinal in south-eastern Europe. From the correlogram (Fig. 6) no simple pattern of geographic variation can be expected for morphological principal component 2 .

\section{Climate}

Two climatic factors were extracted from the climatic character correlation matrix as explaining $88.7 \%$ of the total interlocality climatic variation. Climatic principal component 1 (CPC1, $47.8 \%$ of explained varaince) showed a significant negative correlation with temperature variables (TJan, $r=-0.56$; TJul, $r=-0.90$; TAnn, $r=-0.84$; SDT, $r=-0.43$, all significant $p<0.005$ ) and a significant positive correlation with precipitation (PJan, $r=0.55$; PJul, $r=0.87$; PAnn, $r=0.87$, all significant $p<0.005$ ). This was considered to reflect increasing humidity and decreasing average temperatures. Climatic principal component 2 (CPC2) explained an additional $40.9 \%$ of the variance. It showed significant correlations with seasonality (SDT, $r=0.83$; SDP, $r=-0.82$, both significant $p<0.001$ ), and a significant negative correlation with January temperature and precipitation levels (TJan, $r=-0.80$; PJan, $r=-0.74$, both significant $p<0.001$ ). Climatic principal component 2 was thus taken mainly to reflect seasonality. Together the first and second climatic principal components form a coordinate system that measures temperature and moisture on the horizontal axis and primarily seasonality on the vertical axis (Fig. 7). The smallest sample (No 5), originating from a cold, wet area, had the highest character loadings for the CPC1. Character loadings of samples from cluster B were negative for CPC1, suggesting a dry, warm climate. Despite considerable overlap between the samples belonging to clusters $\mathrm{A}$ and $\mathrm{B}$, it was evident that summer temperature and moisture were

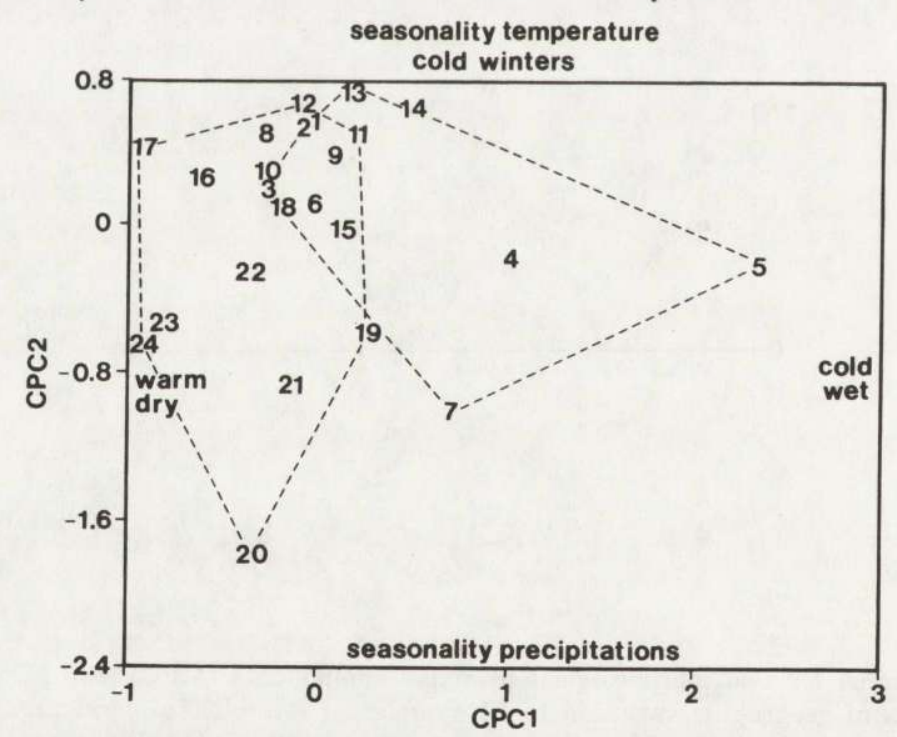

Fig. 7. Projection of 24 sample centroids onto the first two climatic principal components (CPC1 and CPC2). See text for explanation. 
mainly related to size variation. Phenetically large samples from cluster B had either highly positive or highly negative character loadings for CPC2, suggesting that seasonality and winter conditions had no influence on cranial size.

The Mantel test was not significant $(p=0.229)$ when the average taxonomic distance matrix between samples and the climatic-distance matrix between these localities were compared. The combination of the two climatic principal components is thus a poor predictor of phenetic variation. This may be due to the absence of a significant correlation ( $r=-0.15$, not significant) between morphological principal component 1 as a size vector responsible for the majority of the original phenetic variability, and the climatic principal component 2 , which explained nearly half the climatic variation.

Morphological principal component 1 was significantly correlated with climatic principal component $1(r=-0.49, p<0.05)$ and with three climatic variables (PJul, $r=-0.60, p<0.01$; PAnn, $r=-0.43, p<0.05$; TAnn, $r=0.48, p<0.05$ ). In a stepwise regression July precipitation explained $36 \%$ of the variation in morphological principal component $1\left(R^{2}=0.36\right)$, and together with July temperature an additional $4 \%\left(R^{2}=0.40\right.$, Table 1$)$. Forcing five additional climatic variables (i.e. all climatic variables except SDT) into a model resulted in $R^{2}=0.44$. Summer precipitation thus appeared to be a better predictor of Greater horseshoe bat size than summer temperature.

Morphological principal component 2 was significantly correlated only with climatic principal component $2(r=-0.42, p<0.05)$. Seasonality in precipitation (SDP) explained less than $20 \%$ of the varition in morphological principal component $2\left(R^{2}=0.18\right)$ in the first step of stepwise multiple regression. At the

Table 1. Results of stepwise multiple-regression analyses of morphological and climatic variables for 24 geographic samples of Rhinolophus ferrumequinum. The standardized regression coefficients reflect their explanatory power when all variables were entered. The coefficients of multiple determination $\left(R^{2}\right.$ and adjusted $R^{2}$ ) with all variables entered are in parentheses opposite the heading of each set of independent variables. ${ }^{*} \mathrm{~F}$-to-enter $>1$, ${ }^{* *} \mathrm{~F}$-to-enter $>5,{ }^{* * *} \mathrm{~F}$-to-enter $>10$.

\begin{tabular}{ccc}
\hline & Step entered & $\begin{array}{c}\text { Standardised } \\
\text { regression coefficient }\end{array}$ \\
\hline MPC1: & $\left(R^{2}=0.40 ;\right.$ adjusted $\left.R^{2}=0.34\right)$ & \\
PJul & $1^{* * *}$ & -0.111 \\
TJul & $2^{*}$ & -0.018 \\
MPC2: & $\left(R^{2}=0.49 ;\right.$ adjusted $\left.R^{2}=0.39\right)$ & \\
SDP & $1^{* *}$ & 0.015 \\
PJan & $2^{* *}$ & -0.003 \\
TAnn & $3^{*}$ & 0.097 \\
TJul & $4^{*}$ & -0.071 \\
\hline
\end{tabular}


PJan was forced into the model $\left(R^{2}=0.36\right)$. Further inclusion into the model of TAnn and TJul increased the explained variance of MPC2 to $50 \%\left(R^{2}=0.50\right)$. This either suggests that the formation of the interorbital region is under the control of a complex of climatic variables or that climate has no influence on this character at all.

\section{Discussion}

The size variation in Greater horseshoe bat from south-eastern Europe revealed a pattern contrary to Bergmann's rule: namely, the warmer the area, the larger the bat. Such a response to climate is not uncommon among mammals. McNab (1971) argued that "most latitudinally widespread mammals in North America do not follow this (i.e. Bergmann's) rule". Geist (1987, 1990) even concluded that "Bergmann's rule has no basis in fact or theory" and is thus invalid. According to this opinion (Geits 1987) body size correlates directly with the duration of the resource availability. This "resource restriction" hypothesis can also explain size variation in Greater horseshoe bat. The Greater horseshoe bat is an insectivorous hibernator, accumulating energy during the warm (i.e. "suitable") months and hibernating during the cold (i.e. "unsuitable") period. Geist (1987) hypothesized body size to be a "function of how much time growing individuals have unhindered access to food of the highest quality". We could expect that Greater horseshoe bats from colder areas (short "suitable" period) have difficulties in completing ontogeny. Ransome (1973) demonstrated that adverse climatic conditions in April and May result in heterothermy during the gestation period. This affects the length of the gestation period and additionaly reduces the time for postnatal development in Greater horseshoe bats from regions with shorter "suitable" periods. Since large females can produce larger neonates and more or richer milk than small-bodied ones for the same relative investment (compare Geist 1987) this could further affect the bats postnatal growth. So we may hypothesise that bats from colder areas (the northern borders of the distributional area and mountains) are born smaller, obtain less milk (or milk of lower quality) and have less time to complete development. This is becouse they are born later, and start hibernating earlier, than their counterparts from southern regions. In this light the negative Bergmann's response is rationalised in Greater horseshoe bats. Since summer precipitation explained the variation in MPC1 better than summer temperature, it seems that the days suitable for feeding are primarily dry days without rainfall. However, it should be noted that size reduction in colder areas is not common among European bats; positive Bergmann's responses have been reported for Myotis daubentoni in Europe (Bogdanowicz 1990) and Pipistrellus pipistrellus in Britain (Stebbings 1973). Nevertheless, the latitudinal clines in size were associated positively with moisture in Myotis daubentoni (Bogdanowicz 1990).

The Greater horseshoe bat is sedentary. It usually moves little more than 30 $\mathrm{km}$ in a season (Roer 1960, Hill and Smith 1985). Size differences among the 
studied samples may thus be primarily due to selection for homeostatic mechanisms, and as such of little taxonomic significance. The nominate race and $R$. f. martinoi (reported from south-eastern Europe) were discriminated only by size. Here this character was demonstrated to depend upon climate, and to vary somewhat clinally. The recognition of two subspecies thus seems unsubstantiated, even more so because marked overlap was evident in the condylocanine length of the skull in the two size-dependent clusters. Corbet (1978) warns against the use of formal subspecific names for segments of species without objective boundaries. Trinomials should only be used if they actually represent evolutionary subunits.

The palaeontological evidence available does not support the idea of two independent centers of origin for the Greater horseshoe bat, giving rise to cranially smaller (i.e. the nominate form) and larger (i.e. $R$. f. martinoi) groups of populations. According to Topál (1979) the Greater horseshoe bat has a complex phylogenetic history in Central Europe during the Pleistocene. Hungary was populated during the Middle Pleistocene by Rhinolophus ferrumequinum tarkoensis Topál, 1979, a form showing more advanced development of the second upper premolar than modern Greater horseshoe bats. This earlier form became extinct in the Carpathian Basin before the Upper Pleistocene, which suggests that central Europe was colonized by the nominate subspecies of the Greater horseshoe bat comparatively recently. The oldest fossil record from Hungary is from the Upper Pleistocene (Topál 1981). The border od its distribution also fluctuated during the Pleistocene. During the last interglacial (Riss/Würm) its range extended northwards of its range in the Holocene (Horaček and Ložek 1988). In any case, the available evidence suggests that the current border of its distribution was established quite recently. Studying the succession of late Holocene bat faunas at Katerloch (Austria), Bauer and Wiessensteiner (1987) found the Greater horseshoe bat to be the latest species present. Cosequently, I propose that $R$. f. martinoi be considered a synonym of $R$. f. ferrumequinum.

The fact that interorbital constriction is independant of cranial size variation has also been reported in other mammals, e.g. Microtus pennsylvanicus (Snell and Cunnison 1983) and Ondatra zibethicus (Pankakoski and Nurmi 1986). In both studies the interorbital constriction showed no simple pattern of geographic variation (i.e. categorical or clinal), so it was regarded as a character of little taxonomic importance. According to Snell and Cunnison (1983) it is less variable in extreme or northern climates in Microtus pennsylvanicus. Projection of the 24 sample centroids onto the two morphological principal components in the Greater horseshoe bat also revealed larger variation (i.e. extreme values of MPC2 scores) among samples from cluster B (Fig. 1). As mentioned earlier, these are larger bats, living in a supposedly more suitable and less stressed environment, which is in accordance with the findings of Snell and Cunnison (1983).

Acknowledgements: I thank the following persons for allowing me to examine specimens in their care: Drs K. Bauer, J. Gaisler, V. Hanak, D. Mirić, S. Petkovski, B. Petrov, and F. Spitzenberger. Dr J. Gaisler and two anonymous reviewers provided comments on an earlier draft of this manuscript, and H. Griffiths improved the English version. 


\section{References}

Bauer K., Baar A., Mayer A. and Wirth J. 1979. Die wirbeltierfaunistische Durchforschung der Höhlen Österreichs - 15 Jahre Biospeläologische Arbetsgemeinschaft an der Säugetiersammlung des Naturhistorischen Museums. Höhlenforschung in Österreich (Neue Folge 17): 77 - 86.

Bauer K. and Wiessensteiner V. 1987. Die holozäne Fledermausfauna des Katerloches bei Weiz, Steiermark (Mamm., Chiroptera). Mitt. Abt. Zool. Landesmus. Joanneum, Graz. 40: 25 - 40.

Bogdanowicz W. 1990. Geographic variation and taxonomy of Daubenton's bat, Myotis daubentoni, in Europe. J. Mamm. 71: $205-218$.

Caubere B., Menu H. and Saint Girons M.-C. 1968. Notes sur les mammiferes de France. VII. Dimensions de l'avant-bras de Rhinolophus ferrumequinum (Schreber, 1774). Mammalia. 32: $97-103$.

Corbet G. B. 1978. The Mammals of the Palaearctic Region: a taxonomic review. British Museum (Nat. Hist.) and Cornell University Press, London: 1 - 314.

Djulic B. and Felten H. 1964. Säugetiere (Mammalia) aus Dalmatien, 2. Senck. biol. 45: 93 - 98.

Djulić B. and Mirić D. 1967. Catalogus faunae Jugoslaviae, IV/4 Mammalia. Academia Scientarum et Artium Slovenica, Ljubljana: 1 - 46.

Ellerman J. R. and Morrison-Scott T. C. S. 1966. Checklist of Palaearctic and Indian mammals 1758 to 1946. British Museum (Nat. Hist.), London: $1-810$.

Felten H., Spitzenberger F. and Storch G. 1977. Zur Kleinsäugerfauna West-Anatoliens. Teil IIIa. Senckenbergiana biol. 58: $1-44$.

Feriancova-Masarova Z. and Hanák V. 1965. Stavovce Slovenska IV, Cicavce. Vydavatelstvo Slovenskej Akademie vied, Bratislava: $1-331$.

Gabriel K. R. and Sokal R. R. 1969. A new statistical approach to geographic variation analysis. Systematic Zoology. 18: 259 - 278.

Geist V. 1987. Bergmann's rule is invalid. Can. J. Zool. 65: 1035 - 1038.

Geist V. 1990. Bergmann's rule is invalid: a reply to J. D. Paterson. Can. J. Zool. 68: 1613 - 1615.

Görner M. and Hackethal H. 1987. Säugetiere Europas. Neumann Verlag Leipzig: $1-370$.

Hill J. E. and Smith J. D. 1985. Bats. A natural history. British Museum (Nat. Hist.), London: 1 243.

Horacek I. and Ložek V. 1988. Palaeozoology and the Mid-European Quaternary past: scope of the approach and selected results. Rozpravy Ceskoslovenske Akademie ved, Akademia, Praha. 98: $1-102$.

Iliopoulou-Georgudaki J. and Ondrias J. C. 1986. The greater horseshoe bat, Rhinolophus ferrumequinum (Schreber, 1774), in Greece, with description of a new subspecies. Occasional papers The Museum Texas Tech University. 102: $1-8$.

Landsberg H. E., ed. 1977. World Survey of Climatology, Vol. 6, Climates of Central and Southern Europe. Elsevier Scientific Publisher Comp., Amsterdam: 1 - 248.

Manly B. F. J. 1988. Multivariate Statistical Methods. Chapman and Hall, London: $1-159$.

McNab B. K. 1971. On the ecological significance of Bergmann's rule. Ecology. 52: 845 - 854 .

Palmeirim J. M. 1990. Bats of Portugal: Zoogeography and Systematics. The University of Kansas, Museum of Natural History, Miscellaneous publications. 82: $1-53$.

Pankakoski E. and Nurmi K. 1986. Skull morphology of Finnish muskrats: geographic variation, age differences and sexual dimorphism. Ann. zool. Fenn. 23: 1-32.

Petrov B. M. 1941. Zamjatki po sistematike i ekologije mlekopitajoših jožnoj Serbii. Zapiski Ruskago Naučnago Instituta v Bjelgradi. 16: 57 - 64. [In Russian with English summary]

Ransome R. D. 1973. Factors affecting the timing of births of the greater horse-shoe bat (Rhinolophus ferrumequinum). Period. biol. 75: 169 - 175.

Roer H. 1960. Vorläufige Ergebnisse der Fledermaus-Beringung und Literaturübersicht. Bonn. zool. Beitr. 11: $234-263$. 
Rohlf F. J. 1989. NTSYS-pc. Numerical Taxonomy and multivariate analysis system. Exeter publishing, Ltd., New York, unpaged.

Snell R. R. and Cunnison K. M. 1983. Relation of geographic variation in the skull of Microtus pennsylvanicus to climate. Can. J. Zool. 61: 1232 - 1241.

Sokal R. R. 1978. Spatial autocorrelation in biology. 1. Methodology. Biol. J. Linnean Soc. 10: 199 228.

Stebbings R. E. 1973. Size clines in the bat Pipistrellus pipistrellus related to climatic factors. Period. biol. 75: $189-194$.

Steinhauser F. 1970. Climatic Atlas of Europe. Maps of mean temperature and precipitation. WMO UNESCO, Cartographia, Budapest, unpaged.

Topál G. 1979. Fossil bats of the Rhinolophus ferrumequinum group in Hungary (Mammalia: Chiroptera). Fragm. Min. et Pal. 9: 61 - 102.

Topál G. 1981. Bat remains from the Upper Pleistocene localities at Süttò, Hungary. Fregm. Min. et Pal. 10: $65-70$.

Received 27 July 1992, accepted 31 March 1993. 